\title{
II. GREETINGS BY THE BOARD OF THE MECHANICS DIVISION OF THE NATIONAL ACADEMY OF SCIENCES OF UKRAINE
}

\author{
B. E. Paton, V. L. Bohdanov, A. F. Bulat
}

Dear colleagues!

The Presidium and the Mechanics Division of the National Academy of Sciences of Ukraine are happy to congratulate scientists, engineers, and all the staff of the S. P. Timoshenko Institute of Mechanics on the 100th anniversary of its foundation.

The Institute was the first scientific technical establishment founded within the National Academy of Sciences of Ukraine. The Institute has contributed considerably to the development of the world science, gained a lot of important results that constituted a basis of new methods and approaches of modern mechanics.

Since its early years the Institute has intensively studied the fatigue mechanisms of bridge and boiler steel, the strength of bridge elements and machine parts depending on mechanical factors and processing conditions, solved problems of the dynamic strength of military structures, studied the stability of engineering structures within and beyond elasticity, developed the traditional fields of the theory of elasticity and thermoelasticity, theory of shells, stress concentrations, fatigue, strength, and plasticity of materials and structural elements.

Scientists of the Institute have made it possible to develop new scientific fields, such as the mechanics of composites of deterministic and stochastic structure, the three-dimension theory of stability and wave dynamics of deformable bodies, the theory of coupled mechanical and physical fields in structural elements, numerical methods of the theory of shells, the analytical mechanics of polyaggregate systems, the nonlinear theory of vibrations of solids and bodies with fluid.

The creation of the world-famous Krylov-Bogolyubov-Mytropolsky school of nonlinear vibrations was a great achievement which determined the further development of mechanics.

The results obtained at the Institute have been applied in space, aircraft, ship-building, and other industries.

Today, the Institute continues research in the fields of the mechanics of composites and inhomogeneous media, shell systems, fracture and fatigue, dynamics and stability of mechanical systems.

Your highly professional, hard-working, and talented team is working tirelessly to enhance the economic and industrial development of our country.

Achievements of the Institute have been awarded by numerous State Prizes and Prizes named after prominent scientists, other state awards.

We wish the S. P. Timoshenko Institute of Mechanics of the National Academy of Sciences of Ukraine good health, happiness, creative inspiration and further achievements in the science of Ukraine.

President, National Academy of Sciences of Ukraine Principal Academic Secretary, National Academy of Sciences of Ukraine Academician Secretary, Department of Mechanics of NASU 